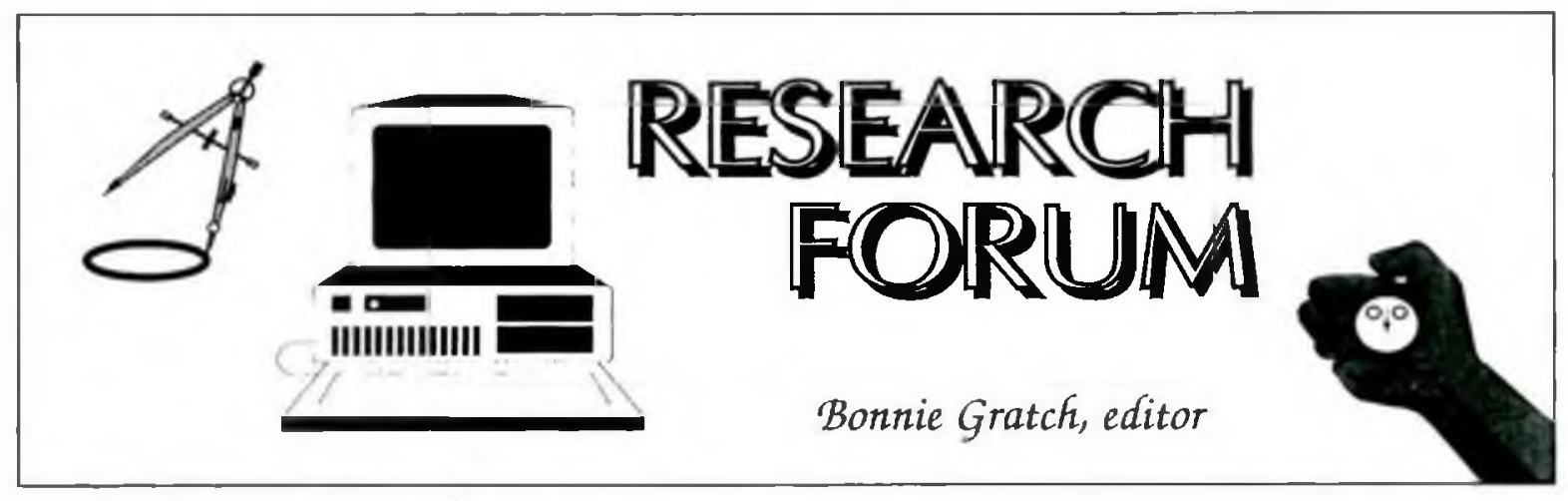

\title{
Af Academic community analysis: Discovering research needs of graduate students at Bowling Green State University
}

\author{
By Marilyn Parrish \\ Reference Librarian \\ Bowling Green State University
}

To be successful in reaching the goal of producing life-long learners who are information literate, we need to teach students how to understand their specific information needs and provide ways for those needs to be met. During an 18-month period (fall 1987-spring 1989) I carried out on a part-time basis a large-scale study of graduate students and their research behavior at Bowling Green State University (BGSU). Graduate students were selected because they make heavy use of the library and have been identified as a priority by the university administration. The goal of this study was to better understand the research environment in which graduate students function. The following summary describes the methodology and highlights some of the data findings. The full report, Analysis of Graduate Student Research at Bowling Green State University by Marilyn Parrish, has been submitted to ERIC.

The model of academic community analysis used here is based on the methodology employed by public libraries to better understand and serve their clientele, particularly the work of Roger Greer and Marty Hale in developing community analysis studies.' It is a descriptive type of community

'Roger C. Greer and Martha L. Hale, "The Community Analysis Process," in Jane RobbinsCarter, Public Librarianship (Littleton, Colo.: Libraries Unlimited, 1982), 358-66. See also H. Achleitner and E. Neroda, "Community Analysis in a Bi-Cultural University Milieu," in Proceedings of survey which provides the basis for better understanding the informational relationships which exist within a particular community. This type of multimethod approach has not been traditionally applied to academic library user groups. It utilized a multidimensional data collection approach which consisted of an analysis of library and graduate college data; interviews with department chairs/ graduate advisers; a syllabus study of graduate courses; and a questionnaire sent to all graduate students.

\section{Collection of available data}

The first step in this process was to collect every available piece of information about graduate students. Printed materials, descriptions of services provided, annual reports, and statistical reports were collected from the graduate college, other related organizations on campus, and from within the library. These data were organized into broad groups relating to demographics, academic programs, and services.

Examination of these data resulted in a different picture of the average graduate student at BGSU than expected. Overall there are more part-time students than full-time students in graduate programs. Nearly half of all graduate students are over

the 7th Annual Meeting, South-Central Regional Group, Medical Library Association, Oklahoma City, 1978,pp. 68-83. 
$30 ; 66 \%$ of the part-time students are over 30 ; and $74 \%$ of the international students are from Asian countries. Extremely surprising to the public services librarians was the finding that only $22 \%$ of the graduate students attend the university-wide, oneweek graduate orientation sessions, and the percentage of these who select library/research skills instruction sessions is even smaller.

Analysis of library statistics (library user education, database searching, interlibrary loan, and circulation) resulted in several significant findings. Examination of interlibrary loan requests $(993$ filled request forms, which is a sample of $8 \%$ of the requests made over a three year period) reveal that the highest number of requests were for materials in the areas of health and human services, English, and history. While ILL was used by $50 \%$ of those graduate students who responded to the questionnaire, in 1987-88, only $8 \%$ of the total number of graduate students and $12 \%$ of the graduate faculty had database searches done for them.

\section{Interviews}

Department chairs/graduate advisers of $17 \mathrm{de}-$ partments were interviewed for this study (these included all of the Ph.D. departments and three of the larger masters programs). Questions asked included: basic information concerning the number of students (with and without funding); percentage of students who complete degree program; percentage of students whowrite theses; the nature of research in their field; skills which are necessary to succeed in the field; how those skills are learned; common problems faced by students; and availability of funding for database searches.

Most of the graduate programs were described as interdisciplinary. This finding is apparent by the types of research topics graduate students choose to pursue, the courses which are offered within departments, the number of students who take courses in related disciplines, and the problems associated with accessing materials. Common problems for graduate students (identified by interviewees) include time management and access to library materials for research. These access problems include materials checked out or missing, or specialized resources not in the library collection. Surprisingly, not all faculty interviewed were aware that they could access the library's online catalog via their office or home computer.

\section{Syllabus study}

After a written request to all graduate faculty, and then a second request to department chairs, 360 course syllabi were obtained for analysis. Of these, 324 were usable, which represents 39 departments/programs and approximately $25 \%$ of the total number of courses listed in the graduate catalog, although the percentage is probably higher since many of the courses listed are not currently offered.

This data collection method focused on gaining an understanding of the assignments required in graduate courses which made use of library materials. The syllabi were examined for the following course requirements: research papers, theme papers (not involving library research), literature reviews, bibliographies, research projects, oral presentations, keeping up with current reading in the field, and the use of reserve materials. Mention of library presentations was also noted. Data analysis was carried out using Lotus 1-2-3. It shows a wide variety of assignments requiring the use of the library. Research methods classes tend not to assign one long research paper but to instruct students through requiring many smaller research assignments. Only $41 \%$ of the courses require students to write a research paper.

\section{Questionnaire}

Much of the information collected for this study is about the environment in which graduate students carry out their research, so hearing from graduate students, themselves, is essential in fully understanding what research opportunities and obstacles they face. The questionnaire was intentionally developed to yield information about their research environment, not an evaluation of library services. Additionally, it was purposefully administered to all graduate students, not limited to those using the library, so that both library users and nonusers would be included.

Questionnaires were mailed to the 1,799 currently enrolled graduate students in January of 1988 , followed by a second mailing to those students who had not responded. Completed questionnaires were returned by 826 students, resulting in a $46 \%$ response rate. In addition to the basic demographic information, students were asked about the number and types of assignments required in their graduate courses; how they picked topics for their research assignments; areas of difficulty in research; data collection in thesis or dissertation research; which library resources and services they had used; and what previous library research experience they had had before their current degree program. Many of the questions offered the opportunity for students to express answers not anticipated and to detail ways in which the library might further assist them in their research. Data analysis was accomplished using SAS.

Findings reveal that respondent characteristics are quite similar to the graduate student population, except that more of the respondents were fulltime. The vast majority of respondents worked at 
least 11-20 hours each week and almost half worked 31 hours or more each week. Graduate students are not solely dependent on the BGSU library collection for their research, as more than half said they use other libraries. It is significant (though not surprising) that most of the students writing theses and dissertations did not examine the library collections before deciding on their topics. However, $82 \%$ of the students made use of library materials in their thesis or dissertation research.

Although most students had some experience with library research before beginning their degree program, they experienced difficulties with many parts of the research process. More than half of the respondents made use of librarians, and said that assistance at the reference desk was most helpful in reducing time spent looking for material. Many of the written comments indicate that these students lacked an awareness about basic library services and would like the library to publicize its services more effectively.

\section{Conclusions and outcomes}

The most common research problems facing graduate students at BGSU include time management and access to materials. Many faculty members assume that students know how to do research by the time they get to graduate school, but the data demonstrate that students experience difficulty with each step of the research process and about two-thirds had received only basic library orientation. Many graduate students pursue research that is interdisciplinary in nature, which results in the

\section{C\&RL News production now computerized}

You may notice a slightly different look for C\&RL News, beginning with this issue, because we are now using Aldus PageMaker software for page layout and composition. This means that instead of spending hours preparing the magazine with scotch tape and scissors, we now spend hours with a mouse and computer screen.

Major elements, such as the fonts we use and the type size, have remained pretty much the same (we are still using Caledonia, but a different version of it that looks rounder and more elegant). The big difference, in addition to reducing our composition costs even further, will be an increased control over the design elements that go into every page. We also expect graphic improvements (note the new column heads in this issue) with the use of such additional software as Corel Draw! and Microsoft Excel.-GME need to access a wide variety of materials.

As might be expected, faculty members are key factors in successful graduate education. Most students described their advisers as helpful, and most find out about services that the university provides through their classes. Yet many of these faculty members are not aware of library research services available for themselves and their students.

The library staff's response to the data findings is still evolving. A study committee has drafted recommendations, which address most of the needs documented by this study. Both the study report and committee recommendations have been distributed to all deans, department chairs, and the vice-president for academic affairs. These recommendations focus on the areas of publicity, library user education/reference services, automated bibliographic access, physical access, and collection development/management. Examples of new or enhanced services for graduate students resulting from the findings of this study will be an improved individual research consultation service with subject specialist librarians for targeted departments; a new brochure describing services to graduate students which will be mailed to their homes and distributed to graduate faculty; and other strategies for orienting graduate students besides the university-wide orientation week.

This multi-methods approach offers important benefits to academic libraries, as users can be studied from a variety of vantage points. The variety of data collection methods ensures the opportunity to corroborate findings. Valuable assistance was provided by the university research and statistical consulting offices, services that are available on most campuses. The end result of analyzing and interpreting these data is well worth the effort and may reveal a surprisingly different view of users than anticipated. Needs are more clearly understood, and new ways of reaching those users are likely to be suggested by the data findings.

\section{Directory of curriculum centers}

The ACRL Education and Behavioral Sciences Section is currently compiling a mailing list of curriculum centers serving teacher education institutions for the third edition of its Directory of Curriculum Centers, scheduled for publication in 1990. If you are interested in being included in the Directory, you may request a questionnaire from Donald V. Osier, Education/Psychology Reference, 110 Walter Library, University of Minnesota, Minneapolis, MN 55455; (612) 624-5718. The deadline is October 1, 1989. 


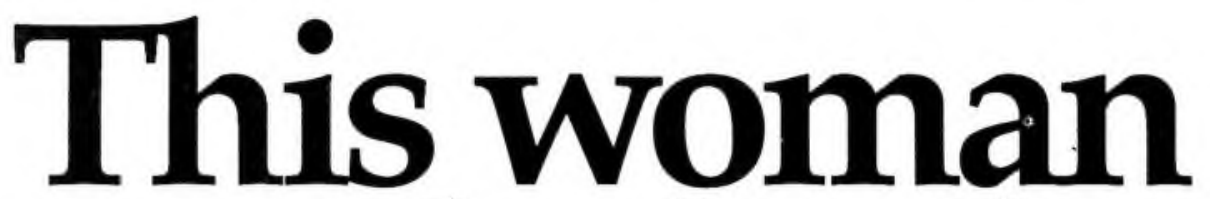

revolutionized

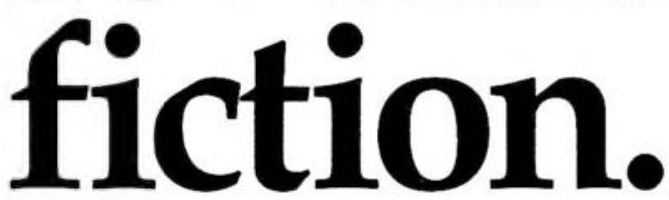

When Virginia Woolf experimented with new forms of fiction, she changed the way many authors approach the novel.

Today, the Arts \& Humanities Citation Inde $x^{\text {TM }}$ is changing the way many librarians approach arts and humanities research.

Its multidisciplinary coverage spans over 1,200 journals and 25 fields of study in the arts and humanities. And more. Because the $A \mathcal{E} H C I^{\mathrm{TM}}$ selectively covers articles from over 4,600 journals in the sciences and social sciences as well. Giving you single-source access to all literature relevant to your patrons' topics.

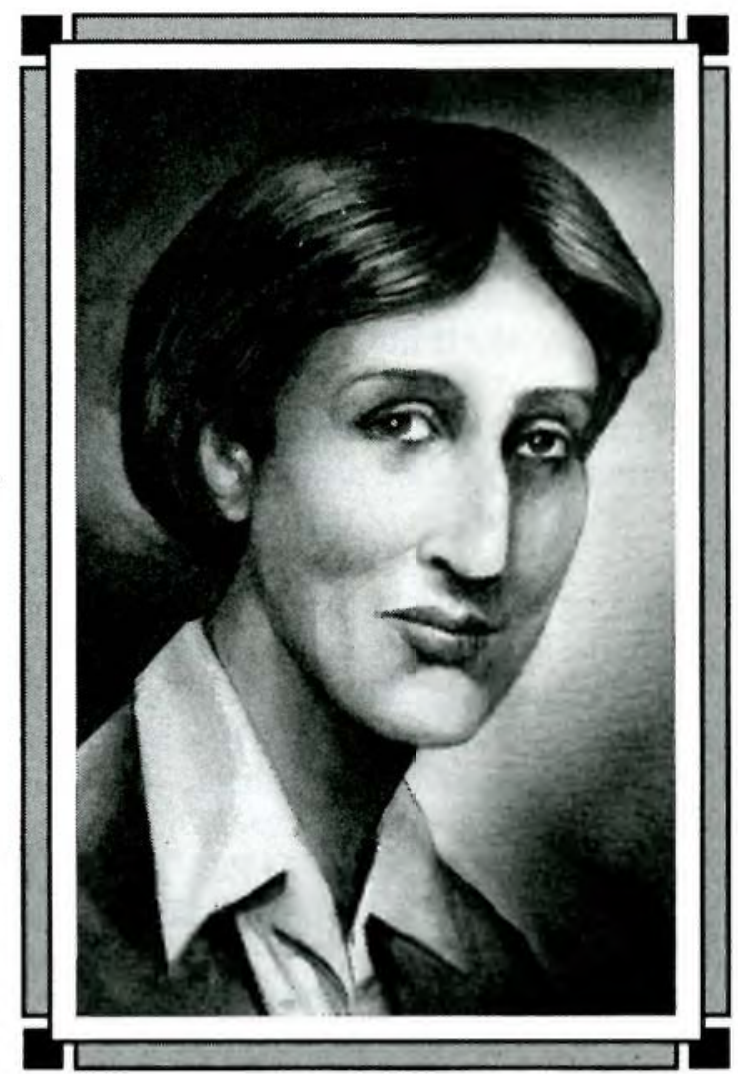

In the case of Virginia Woolf, the $A \mathcal{E} H C I$ lets you quickly find every recent article that cites her work. Not only papers that review her writing itself, but those that examine the psychological factors behind her creative genius...the philosophical and social ramifications of her ideas...as well as her influence on other authors, from E.M. Forster to Simone de Beauvoir.

It's the one resource that leads you across the boundaries of discipline. With the most timely coverage available today. And the greatest efficiency, with 4 access points. Giving you searching power no other single index can match.

To receive a free sample issue of the $A \& H C l$, call toll-free 1-800-523-1850, extension 1405. Or write to the address below.

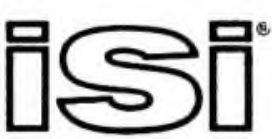

Institute for Scientific Information ${ }^{\circledR}$

3501 Market Street, Philadelphia, Pennsylvania 19104 U.S.A.

(215) 386-0100, extension 1405 